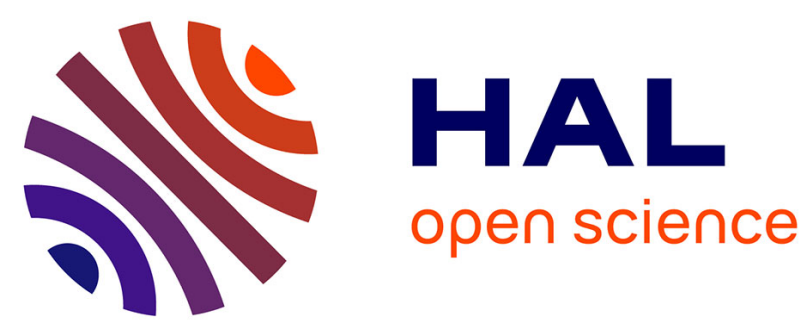

\title{
Transfers from Earth to LEO and LEO to interplanetary space using lasers
}

Claude R. Phipps, Christophe Bonnal, Frédéric Masson, Michel Boustié, Laurent Berthe, Matthieu Schneider, Sophie D Baton, Erik Brambrink, Jean

Marc Chevalier, Laurent Videau, et al.

\section{To cite this version:}

Claude R. Phipps, Christophe Bonnal, Frédéric Masson, Michel Boustié, Laurent Berthe, et al.. Transfers from Earth to LEO and LEO to interplanetary space using lasers. Acta Astronautica, 2018, 146, pp.92-102. 10.1016/j.actaastro.2018.02.018 . hal-02162240

\section{HAL Id: hal-02162240 \\ https://hal.science/hal-02162240}

Submitted on 21 Jun 2019

HAL is a multi-disciplinary open access archive for the deposit and dissemination of scientific research documents, whether they are published or not. The documents may come from teaching and research institutions in France or abroad, or from public or private research centers.
L'archive ouverte pluridisciplinaire HAL, est destinée au dépôt et à la diffusion de documents scientifiques de niveau recherche, publiés ou non, émanant des établissements d'enseignement et de recherche français ou étrangers, des laboratoires publics ou privés. 


\title{
Transfers from Earth to LEO and LEO to interplanetary space using lasers
}

\author{
Claude R. Phipps ${ }^{\mathrm{a}, *}$, Christophe Bonnal ${ }^{\mathrm{b}}$, Frederic Masson ${ }^{\mathrm{b}}$, Michel Boustie ${ }^{\mathrm{c}}$, Laurent Berthe ${ }^{\mathrm{d}}$, \\ Matthieu Schneider ${ }^{\mathrm{d}}$, Sophie Baton ${ }^{\mathrm{e}}$, Erik Brambrink ${ }^{\mathrm{e}}$, Jean-Marc Chevalier ${ }^{\mathrm{f}}$, Laurent Videau ${ }^{\mathrm{g}}$, \\ S'everine A.E. Boyer ${ }^{\text {h }}$
}

a Photonic Associates, LLC, Santa Fe, NM, 87508, USA

${ }^{\mathrm{b}}$ CNES, Direction des Lanceurs, 52 Rue Jacques Hilairet, 75612, Paris Cedex, France

${ }^{\mathrm{c}}$ CNRS-Universite Poitiers, Poitiers, France

${ }^{\mathrm{d}}$ CNRS-Arts et Metiers ParisTech, Paris, France

${ }^{\mathrm{e}}$ LULI, CNRS- École Polytechnique, Palaiseau, France

${ }^{\mathrm{f}}$ CEA, DAM, CESTA, Paris, France

${ }^{\mathrm{g}}$ CEA, DAM, DIF, Paris, France

${ }^{\mathrm{h}}$ Mines ParisTech, CEMEF PSL, Paris, France

\section{A R T I C L E I N F O}

\section{Keywords:}

Laser ablation

Laser-produced plasma

Ultrashort lasers

Laser space propulsion

\begin{abstract}
A B S T R A C T
New data on some materials at $80 \mathrm{ps}$ pulse duration and $1057 \mathrm{~nm}$ wavelength give us the option of proportionally combining them to obtain arbitrary values between 35 (aluminum) and 800 N/MW (POM, polyoxymethylene) for momentum coupling coefficient $\mathrm{C}_{\mathrm{m}}$. Laser ablation physics lets us transfer to LEO from Earth, or to interplanetary space using repetitively pulsed lasers and $C_{m}$ values appropriate for each mission. We discuss practical results for lifting small payloads from Earth to LEO, and space missions such as a cis-Mars orbit with associated laser system parameters.
\end{abstract}

\section{Introduction}

The physics of small payload transfers from Earth to low Earth orbit (LEO) using laser ablation propulsion concepts, as well as for laser propulsion in space were considered in some detail in earlier work [1], [2]. There are many other applications for this technology in space [3]. We predicted that costs of small-target transfers to LEO using this technique could be far below today's $\$ 10,000 / \mathrm{kg}$ with multiple launches per day. Missing from these early reports was data on particular ab materials giving practical values of the mechanical coupling coefficient $\mathrm{C}_{\mathrm{m}}$. The history of photon propulsion begins ninety years ago with Tsander [4], Tsiolkovsky [5] and Oberth [6], leading to today's "solar sails." In 1953, Sfinger published his concept for photon rockets [7] well before the invention of lasers.

However, for usefully large forces - for example, enough to counteract gravity or accelerate a several-kg object to orbital speeds in a short time, laser ablation propulsion is more attractive than pure photon propulsion.

Laser ablation propulsion operates, ideally in vacuum, by inducing a jet of vapor and plasma from a target using a laser pulse, which transfers momentum to the target (Fig. 1) [8]. Terminology is explained in more detail in our review of the field [9].

\section{Purpose of this paper}

The purpose of this paper is to update the reference [2] analysis of propulsion into low Earth orbit (LEO) by including direct launch from the Earth, and to extend the analysis to interplanetary transfers at much higher velocity using new impulse coupling data we recently obtained. We first briefly review the physics and history of this field, then discuss the two applications. When mission duration is at a premium and laser power is not, we will show that $\mathrm{C}_{\mathrm{m}}$ as low as $70 \mathrm{~N} / \mathrm{MW}$ is a good optimum for getting from LEO to Mars and 100-150 N/MW from ground to LEO.

\section{Laser momentum transfer physics}

The laser impulse coupling coefficient $\mathrm{C}_{\mathrm{m}}$ is the ratio of momentum delivered to a target by an ablation jet to the incident beam energy $\mathrm{W}$ for a laser pulse, or of surface pressure to incident intensity,

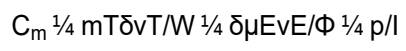




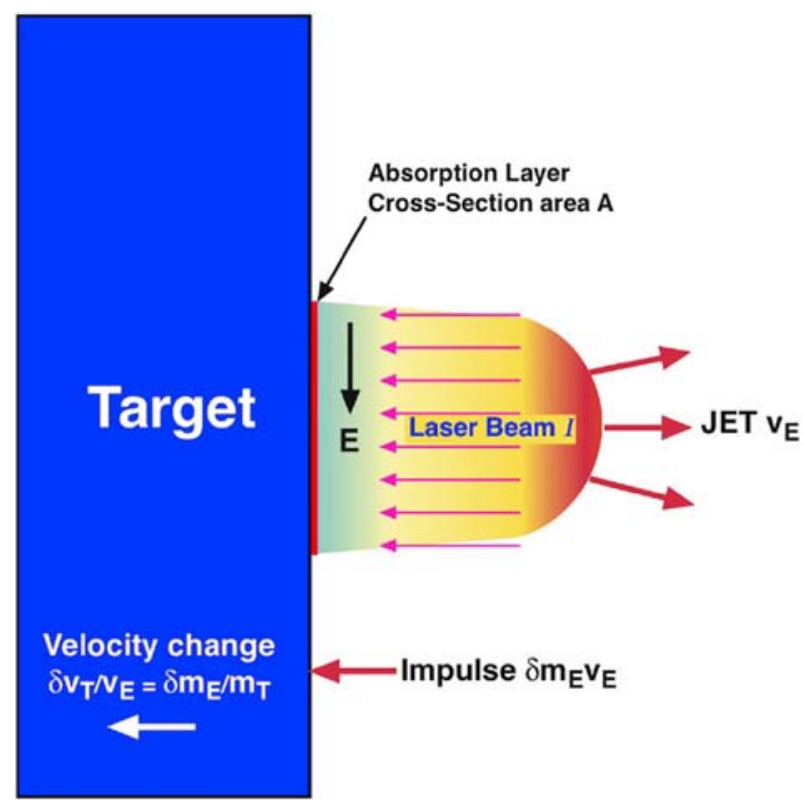

Fig. 1. Impulse from laser ablation.

In Eq. (1), $\mathrm{m}_{\mathrm{T}}$ is target mass, $\mathrm{p}$ is surface pressure at the target, $\mathrm{I}$ is intensity $\left(\mathrm{W} / \mathrm{m}^{2}\right), \Phi^{1 / 4}$ IT is fluence on target $\left(\mathrm{J} / \mathrm{m}^{2}\right), \mathrm{v}_{\mathrm{E}}$ is exhaust velocity of the laser ablation jet and $\delta \mu_{\mathrm{E}}$ is areal mass density $\left(\mathrm{kg} / \mathrm{m}^{2}\right)$ in the ablation jet column created by one pulse. $\mathrm{C}_{\mathrm{m}}$ has dimensions $\mathrm{N}-\mathrm{s} / \mathrm{J}$ or $\mathrm{N} /$ W. $\mathrm{C}_{\mathrm{m}}$ for pure-photon pressure is minute: the "momentum coupling coefficient" for pure radiation reflecting off a polished surface is

\section{$\mathrm{C}_{\mathrm{m}}{ }^{1 / 4} 2 / \mathrm{c}^{1 / 4} 6.7 \mathrm{mN} / \mathrm{MW}$.}

A 10-kW laser reflecting perfectly off a surface would produce a thrust of only $67 \mu \mathrm{N}$. The other important parameter for any type of photon propulsion is propellant exit velocity, $\mathrm{v}_{\mathrm{E}}$, simply c for light, but $\left(2 \mathrm{kT}_{\mathrm{i}} /\right.$ $\left.\mathrm{m}_{\mathrm{i}}\right)^{1 / 2} \ll \mathrm{c}$ for laser ablation propulsion. $\mathrm{T}_{\mathrm{i}}$ and $\mathrm{m}_{\mathrm{i}}$ are ion temperature and mass.

Conservation of energy says that the efficiency of the whole process is $\eta_{A B} 1 / 4 \Psi C_{m} v_{E} / 2$.

The parameter $\Psi \diamond 1$, as we discuss after Eq. (4).

For very long trips, where time is available, solar sails represent a practical use of pure photon propulsion, taking advantage of the fact that, for light in reflection, $\mathrm{I}_{\mathrm{sp}} 1 / 4 \mathrm{c} / \mathrm{g}_{\mathrm{o}}$, a very large number. The factor of 2 in the Eq. (2) value for the $\mathrm{C}_{\mathrm{m}}$ of light arises from the fact that the energy density of light $\mathrm{I} / \mathrm{c}$ is doubled on reflection. At $1 \mathrm{~kW} / \mathrm{m}^{2}$ at our distance from the Sun, a 10-km diameter reflective sail will generate $520 \mathrm{~N}$ thrust. Using this thrust, a $2 \mu \mathrm{m}, 250$-ton Al-coated plastic reflective film with this diameter could accelerate to $3 \mathrm{~km} / \mathrm{s}$ in 17 days. The main problem is how to deploy such a film. Despite decades of development, the largest sail yet deployed (JAXA IKAROS [10], 2010) is $14 \times 14 \mathrm{~m}$.

Variable $v_{E}$ can be achieved by adjusting laser intensity on target - by changing focal spot area, laser pulse duration and energy - which causes exhaust velocity to vary across the range from chemical reactions (approximately $5 \mathrm{~km} / \mathrm{s}$ ) to much higher values easily reaching $50 \mathrm{~km} / \mathrm{s}$. $10,000 \mathrm{~K}$ ion temperatures are readily created by a laser pulse. Exhaust velocity is only a matter of intensity [11]. Thrust can be varied independently of $\mathrm{v}_{\mathrm{E}}$ by changing the laser pulse repetition rate.

\subsection{Ablation propulsion with pulsed lasers}

Ablation efficiency is defined as in Eq. (3) where u is drift velocity: $\psi \stackrel{1 / 4}{2}\left\langle v_{x}>\mid<v_{x}\right\rangle \stackrel{2}{1 / 4}\left(u^{2} \mathrm{p} 2 \mathrm{kT} / \mathrm{m}_{\mathrm{e}}\right) / \mathrm{u}^{2}$

This parameter $\Psi$ is the result of the fact that the exhaust velocity distribution is a drifting maxwellian with a nonzero mean velocity. However, it can be shown [12] that high intensity ablation plumes correspond to $\Psi: \cdots 1.15$, and we will assume $\psi^{1 / 4} 1$ for simplicity in

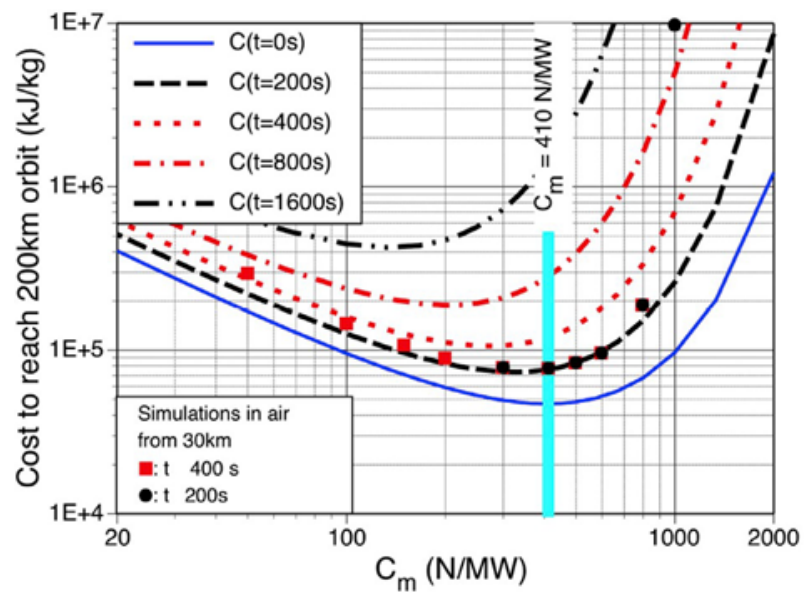

Fig. 3. Results from simulations of laser-powered flights to LEO [2] (with different assumptions than the present work).
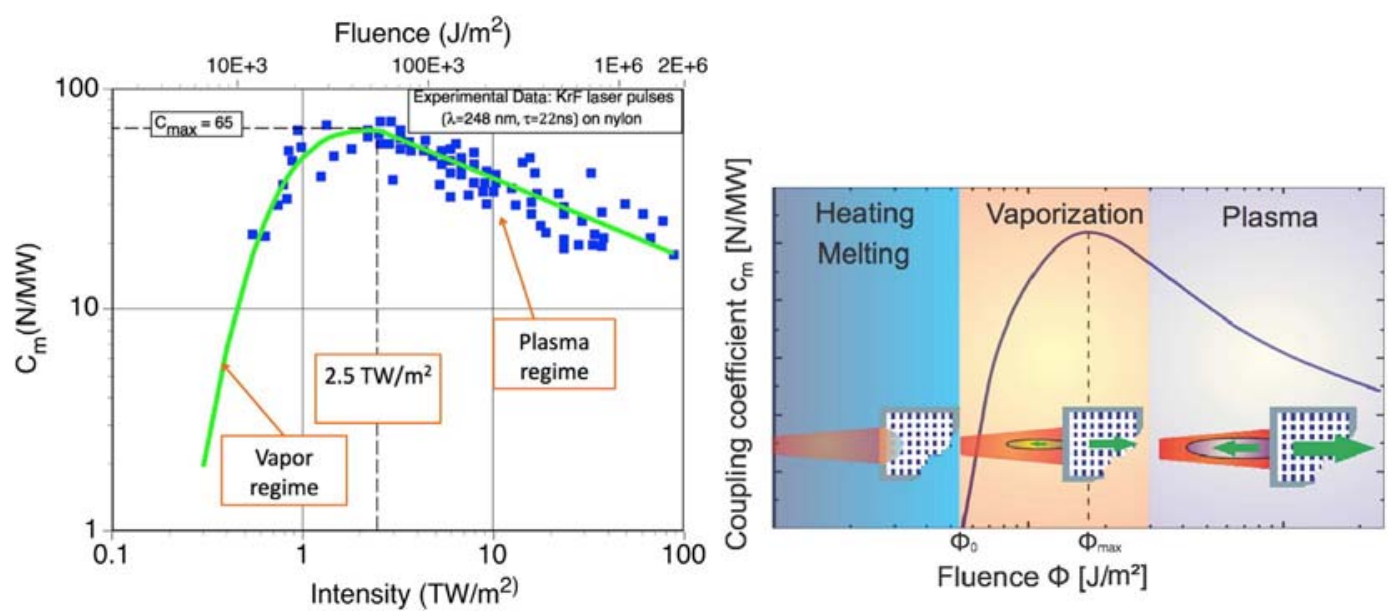

Fig. 2. Illustrating optimum coupling $\mathrm{C}_{\mathrm{mopt}}$ and fluence $\Phi_{\mathrm{opt}}{ }^{1 / 4} \mathrm{I}_{\mathrm{opt}} \mathrm{T}$ which occur when parameters are those to produce maximum $\mathrm{C}_{\mathrm{m}}$. Both vapor and plasma regime theory must be considered to find this optimum. 


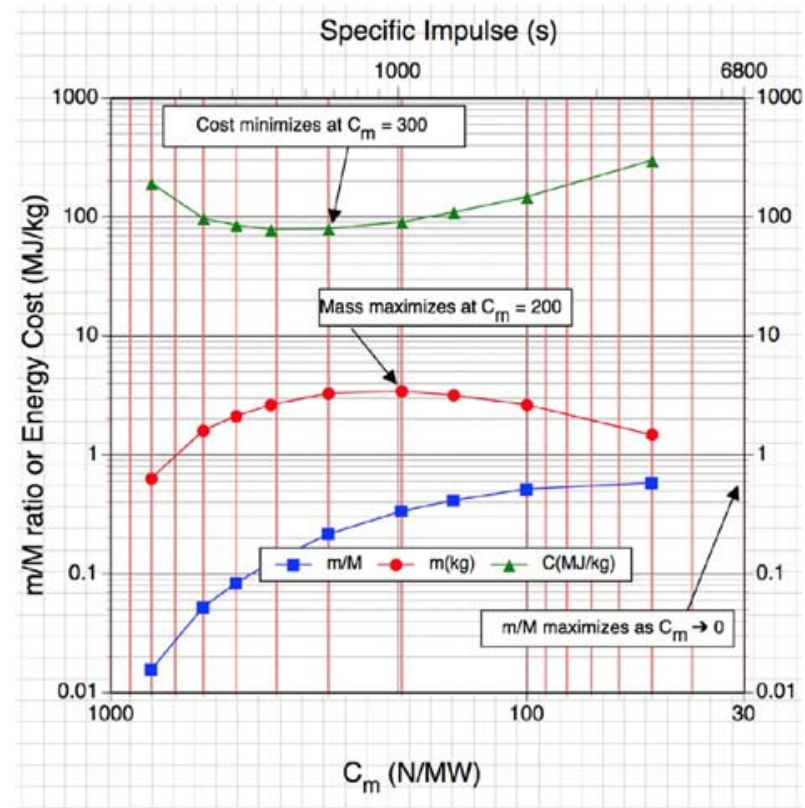

Fig. 4. Simulations in Ref. [2] showed that mass, mass ratio and cost optimize at different values of the coupling coefficient $\mathrm{C}_{\mathrm{m}}$.

Table 1

New laser momentum coupling results $(1057 \mathrm{~nm})$.

\begin{tabular}{lllllll}
\hline Material $\rightarrow$ & & $\mathrm{Al}$ & & POM & \\
\cline { 6 - 7 } Pulsewidth & & $\mathrm{C}_{\mathrm{m}}(\mathrm{N} / \mathrm{MW})$ & $\Phi\left(\mathrm{kJ} / \mathrm{m}^{2}\right)$ & & $\mathrm{C}_{\mathrm{m}}(\mathrm{N} / \mathrm{MW})$ & $\Phi\left(\mathrm{kJ} / \mathrm{m}^{2}\right)$ \\
\hline $400 \mathrm{fs}$ & $28 \pm 3$ & $50 \pm 20$ & & $125 \pm 12$ & $32 \pm 6$ \\
$80 \mathrm{ps}$ & $28 \pm 3$ & $30 \pm 7$ & & $773 \pm 70$ & $40 \pm 8$ \\
\hline
\end{tabular}

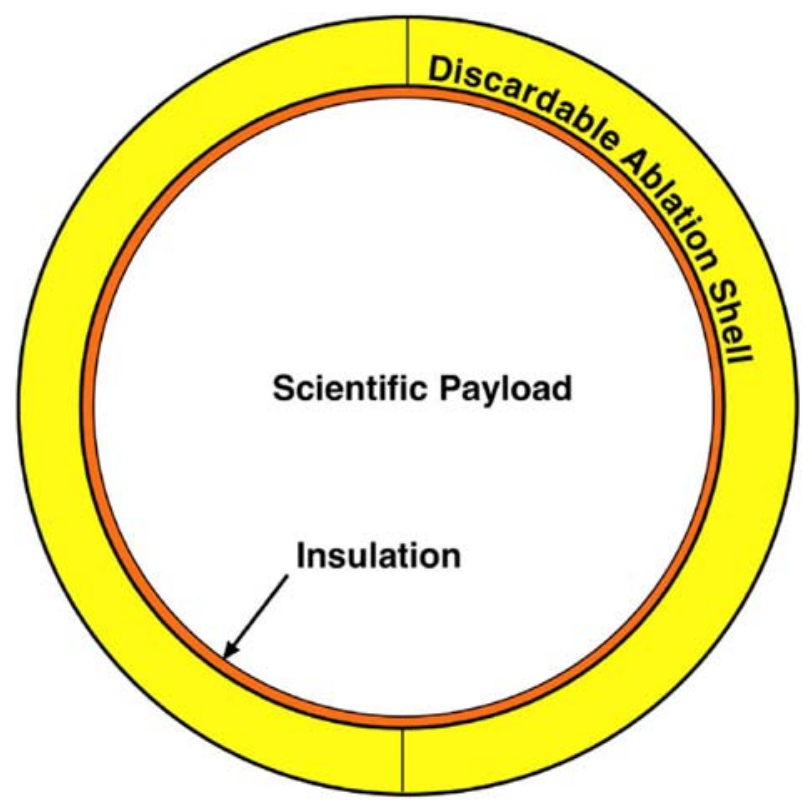

Fig. 5. Laser-propelled flyer.

discussing efficiency. If $\psi$ is larger, Eq. (3) shows it's a bonus for $\eta_{A B}$. The change in velocity of the target from a single pulse is

$\delta \mathrm{v}_{\mathrm{T}}{ }^{1 / 4} \mathrm{C}_{\mathrm{m}} \Phi / \mu_{\mathrm{T}}$

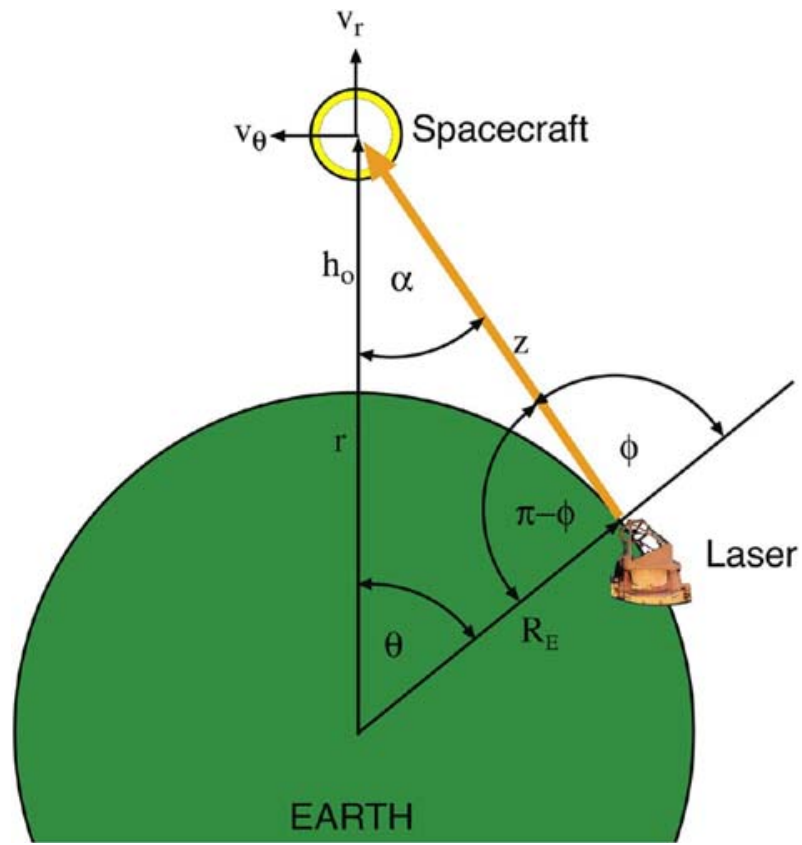

Fig. 6. Geometry for laser launch.

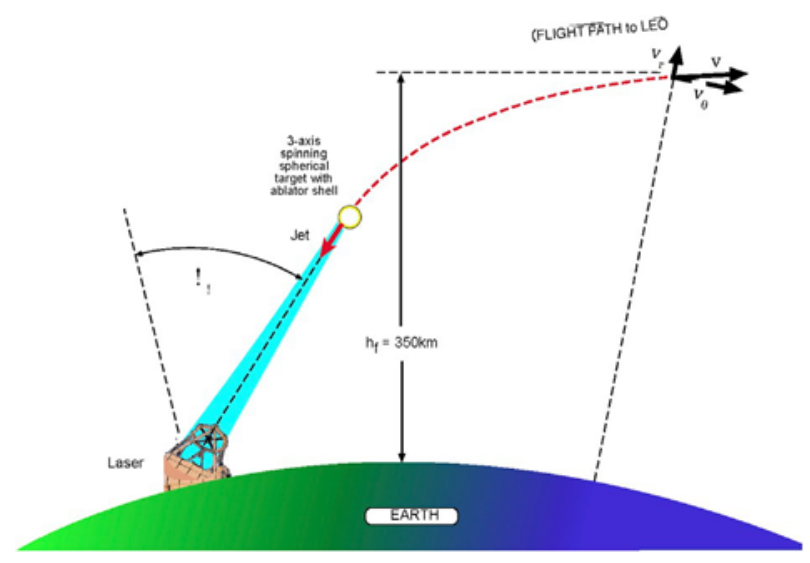

Fig. 7. Laser station inserts the target into orbit. $\mathrm{h}_{\mathrm{f}}$ is final altitude.

and

$\delta v_{T j j} 1 / 4 \eta_{c} C_{m} \Phi / \mu_{T}$.

In Eqs. (5) and (6), $\mu_{\mathrm{T}}$ is the target's areal mass density, $\eta_{\mathrm{c}}$ is an average geometrical efficiency factor taking account of the shape of the target and the fact that the ablation jet will be normal to each facet of its surface, not necessarily antiparallel to the laser beam. The quantity $\delta_{v_{T j j}}$ is the change in target velocity in the beam direction. Eq. (6) is a numerically convenient formulation for space applications because we can deliver a fluence $\Phi$ to a region containing the target and be sure that any object within that region having mass density $\mu_{T}$ and the same $C_{m}$ will gain the same velocity increment from the pulse. This is valid because space debris tend to exist in families with similar $\mu_{\mathrm{T}}$. For direct comparison to electric propulsion engines, the thrust to electrical power ratio is

$C_{m e} 1 / 4 \eta_{e o} C_{m}$.

Laser electrical-to-optical efficiency $\eta_{\varepsilon o}$ can range from 25 to $80 \%$, depending on the laser type. Exhaust velocity can be determined from the product of the easily measured quantities $\mathrm{C}_{\mathrm{m}}$ and $\mathrm{Q}(\mathrm{J} / \mathrm{kg}$ ablated) as follows. Where 
Table 2

Ways to achieve initial target altitu de above denser part of atmosphere.

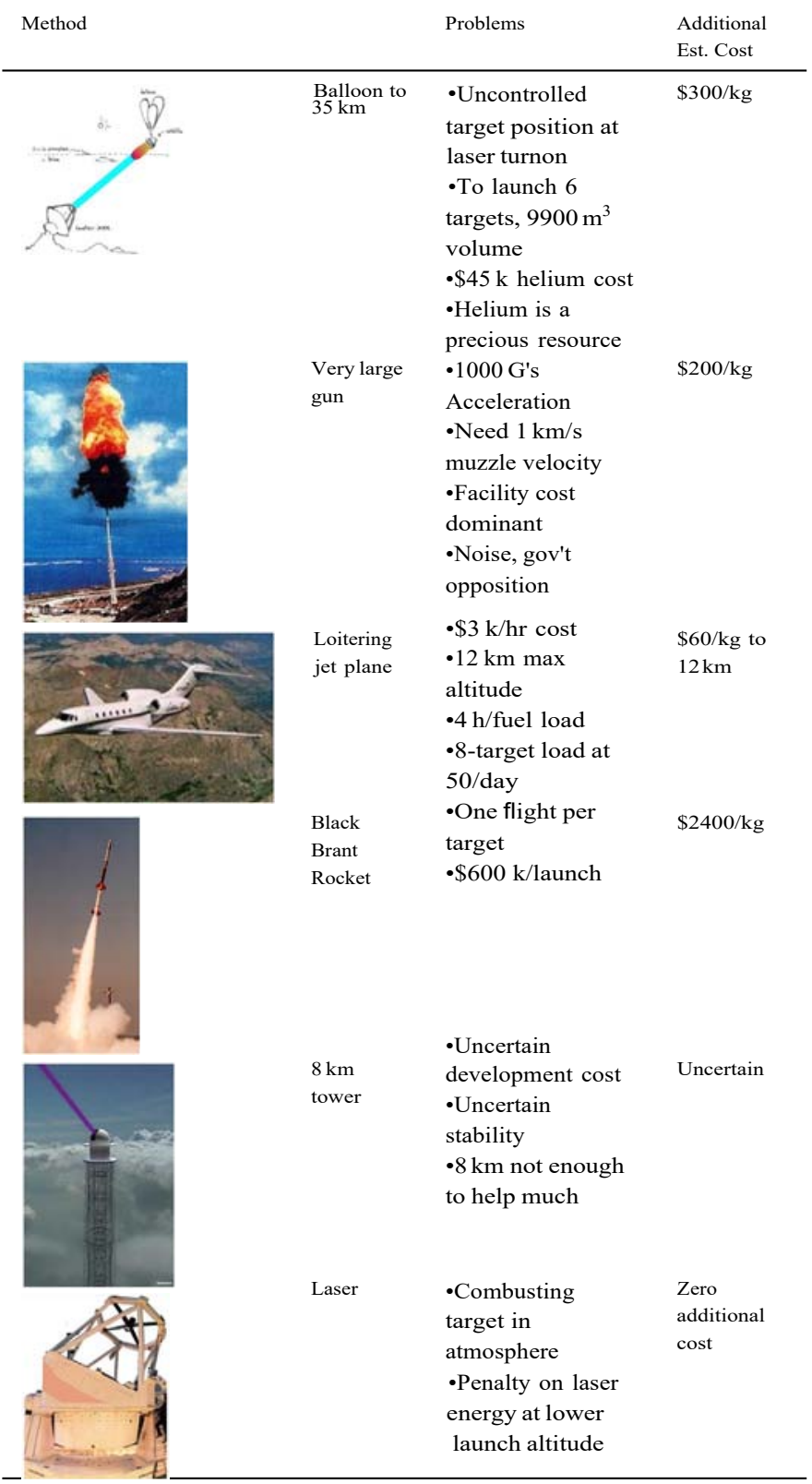

$\mathrm{Q} 1 / 4 \mathrm{~W} / \delta \mathrm{m}_{\mathrm{T}}{ }^{1 / 4} \Phi / \delta \mu_{\mathrm{T}}$

it can be seen dimensionally that the product $\mathrm{C}_{\mathrm{m}} \mathrm{Q}$ must be velocity:

vE $1 / 4 \mathrm{CmQ}$.

Note that $\delta \mu_{\mathrm{T}}{ }^{1 / 4} \delta \mu_{\mathrm{E}}$ by mass conservation. Eq. (9) can be extended to show that ablation efficiency is given by

$\eta_{A B} 1 / 4 C_{m} v_{E} / 2 \frac{1 / 4}{\delta} \delta \mu_{E} v^{2} /(2 \Phi){ }_{1 / 4}^{1 / 4}{ }_{s} b \quad g / 2$,

where $g_{o}$ is the acceleration of gravity and $I_{s p}$ is the so-called specific impulse. $C_{m}$ and $I_{s p}$ are a constant product in which $I_{s p}$ varies inversely with $\mathrm{C}_{\mathrm{m}}$ for engines with the same efficiency. The units of $\mathrm{I}_{\mathrm{sp}}$ are seconds. Another constant product is

$\mathrm{C}_{\mathrm{m}}^{2} \mathrm{Q} / 21 / 4 \mathrm{\eta}_{\mathrm{AB}}$.

Because $\delta \mu_{\mathrm{T}}{ }^{1 / 4} \rho_{\mathrm{T}} \delta \mathrm{x}$, the thickness of the solid target material ablated in one pulse is

$\delta x{ }^{1 / 4} C_{m}^{2} \Phi /\left(2 \rho_{T} \eta_{A B}\right)$

and fuel use rate is

$\mathrm{dm} / \mathrm{dt} 1 / 42 \mathrm{P} \eta_{\mathrm{AB}} /\left(\mathrm{g}_{\mathrm{o}} \mathrm{I}_{\mathrm{sp}}\right)^{2}$

This can equivalently be written

$\mathrm{dm} / \mathrm{dt} 1 / 4 \mathrm{PC}_{\mathrm{m}}^{2} /\left(2 \eta_{\mathrm{AB}}\right)$

In Ref. [2], we took $\eta_{\mathrm{AB}}{ }^{1 / 4} 1$ for simplicity and because $\mathrm{Q}$ (or $\mathrm{I}_{\mathrm{sp}}$ ) were not measured for many materials. This is still true, because these are difficult to measure in single shots.

But we can play a trick: if we write

$\mathrm{C}_{\mathrm{m}}{ }^{1 / 4} \mathrm{C}_{\mathrm{mo}} \eta_{\mathrm{AB}}$

and

$\mathrm{P}^{1 / 4} \mathrm{P}_{\mathrm{O}} / \eta_{\mathrm{AB}}$

Eq. (14) becomes

$\mathrm{dm} / \mathrm{dt}^{1 / 4} \mathrm{P}_{\mathrm{o}} \mathrm{C}_{\mathrm{mo}}^{2} / 2$

a constant as $\eta_{A B}$ varies, as is thrust, $\mathrm{F}^{1 / 4} \mathrm{P}_{\mathrm{o}} \mathrm{C}_{\mathrm{mo}}$. The rate of material ablation is very small. As an example, for an aluminum target (density $\rho_{\mathrm{T}} 1 / 42700 \mathrm{~kg} / \mathrm{m}^{3}$ ), if $C_{\mathrm{m}} 1 / 470 \mathrm{~N} / \mathrm{MW}, \Phi^{1 / 4} 35 \mathrm{~kJ} / \mathrm{m}^{2}$ and $\eta_{\mathrm{AB}} 1 / 41$, Eq. (12) gives $\delta \times 1 / 432 \mathrm{~nm}$. At laser repetition frequency $\mathrm{f} 1 / 450 \mathrm{~Hz}$, even in one minute operation, total ablation depth is $95 \mu \mathrm{m}$. We assume a perfectly uniform beam, such as is achievable with modern methods of apodization.

We note that a consequence of Eqs. (9) and (15) is that the rocket equation for the mass fraction delivered by a flight can be written

$\mathrm{m} / \mathrm{M} 1 / 4 \exp \left(-\mathrm{C}_{\mathrm{mo}} \Delta \mathrm{v} / 2\right)$,

so that especially in space, with a small enough $C_{m o}$ and adequate $P_{0}$, almost any mission is possible.

In the laser propulsion examples given in Figs. 8-12 and Table 3, initial laser average power is $5 \mathrm{MW} / \eta_{\mathrm{AB}}$. It increases as $\eta_{\mathrm{AB}}$ decreases, and $\mathrm{C}_{\mathrm{m}}$ decreases in the same ratio, so that thrust $\mathrm{F}^{1 / 4} \mathrm{PC}_{\mathrm{m}}$ and fuel usage rate are constant. Future measurements will tell us what $\eta_{\mathrm{AB}}$ is.

The laser-produced plasma jet is always perpendicular to the irradiated surface. Temperatures and pressures in plasma that can be achieved by an ultrashort-pulse laser interacting with a target in space range up to $100,000 \mathrm{~K}$ and $100 \mathrm{kbar}$ with velocities of several $\mathrm{km} / \mathrm{s}$.

\subsection{Optima}

There are a number of optima to consider in laser propulsion system design. One is the fluence which gives maximum $C_{m}$. Fig. 2 shows [13, 14] experimental and notional plots of $C_{m}$ values vs. incident fluence $\Phi$ to illustrate this optimum. In other work, we have called this $\mathrm{C}_{\mathrm{m}}$ value and the fluence at which it occurs Cmopt and Фopt.

There is another kind of optimum which gives minimum energy cost to complete a mission. From Fig. 3 , it is clear that $\mathrm{C}_{\mathrm{m}}^{1 / 4} 1000 \mathrm{~N} / \mathrm{MW}$ had an infinite cost for a 200s flight with the parameters of [2]. For these conditions, Fig. 3 shows that each mission had an optimum-cost impulse coupling coefficient. Lines are theory, dots are simulations for a real atmosphere. Flight time depends on laser power. The purpose of Fig. 4 from Ref. [2] is to illustrate these optima. In Ref. [2], initial masses were 10 and $20.4 \mathrm{~kg}$, and delivered payload mass was $6.1 \mathrm{~kg}$. In the present work, we are not trying to minimize energy expenditure. Instead, we are trying to achieve absolute maximum payload mass fraction delivered at the end of the mission. In Ref. [2], initial mass is $25 \mathrm{~kg}$ and delivered mass as

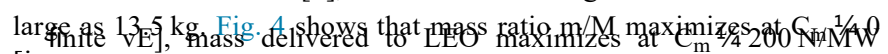
[in $\left(\mathrm{vE}^{1 / 4} 10 \mathrm{~km} / \mathrm{s}\right)$, and cost minimizes at $\mathrm{C}_{\mathrm{m}} 1 / 4300-400 \mathrm{~N} / \mathrm{MW}$. We 


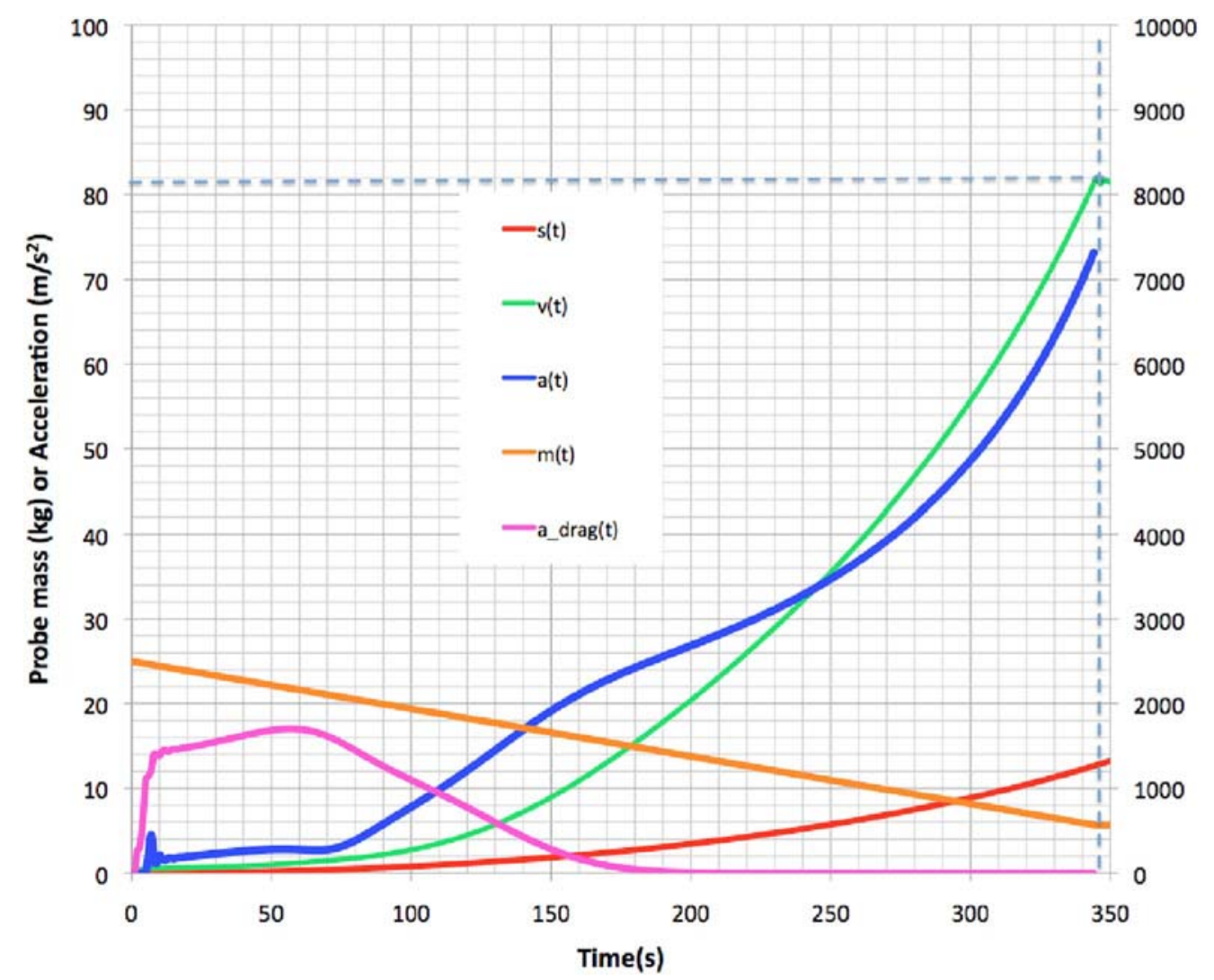

0000

900

8000

000

Fig. 8. Case 3. Single power launch from $1 \mathrm{~km}$ altitude with $C_{m} 1 / 4150 \mathrm{~N} / \mathrm{MW}$. Excessive $\mathrm{v}_{\mathrm{r}}$ produces $-1.6 \mathrm{~km}$ perigee altitude.

assumed $\eta \mathrm{AB} 1 / 41$ in Ref. [2], so exit velocity is $\mathrm{vE} 1 / 42 / \mathrm{Cm}$. These optima are specific to the ref. [2] case. In Ref. [2], delivered mass ratios were much lower than in the present work because we only considered P $1 / 41 \mathrm{MW}$, requiring larger $\mathrm{C}_{\mathrm{m}}$ to counteract gravity and smaller zenith angles. Different results are obtained in the present work which involves higher laser power levels. In consequence, more efficiency is reported in this work. Our work in laser propulsion is to find lasers and materials which achieve a desired optimum.

\section{DIY coupling coefficient}

In experiments conducted at the LULI Laboratory of Keole Polytechnique [15], we measured $\mathrm{C}_{\mathrm{m}}$ on several materials at $400 \mathrm{fs}$ and $80 \mathrm{ps}$, $1057 \mathrm{~nm}$ [Table 1]. In the future we will repeat the measurements at $528 \mathrm{~nm}$, which may be more favorable for $\mathrm{C}_{\mathrm{m}}$. For our purposes, the most important results were for $\mathrm{Al}$ and POM (polyoxymethylene, Delrin ${ }^{\circledR}$ ). The latter material gave very large $C_{m}$ at $10.6 \mu \mathrm{m}$ with the Myrabo [16] flyer, which achieved a flight altitude of $72 \mathrm{~m}$ in air in 2000 [17]. We found very high $\mathrm{C}_{\mathrm{m}}$ for this material at $1057 \mathrm{~nm}, 80 \mathrm{ps}$. The same was not true at $400 \mathrm{fs}$. The $\mathrm{POMC}_{\mathrm{m}}$ is too large for most laser launch projects [see Fig. 3], but it is very useful in this way: we now plan to cast ablation fuel from a mixture of $\mathrm{Al}$ dust and POM to obtain any value we want in the range from 30 to $770 \mathrm{~N} / \mathrm{MW}$ at $80 \mathrm{ps}$. As an example, an A1/POM mixture of $5 \%$ POM and $95 \% \mathrm{Al}$ should give $\mathrm{C}_{\mathrm{m}} 1 / 470 \mathrm{~N} / \mathrm{MW}$. Density of the combination is $2640 \mathrm{~kg} / \mathrm{m} 3$, only slightly different from that of Al. The required fluence $(\sim 30 \mathrm{~kJ} / \mathrm{m} 2)$ is about the same for both materials. For various reasons having to do with available laser hardware at $400 \mathrm{fs}$, this pulse duration is not attractive compared to $80 \mathrm{ps}$, so it doesn't concern us that Cmopt for POM at $400 \mathrm{fs}$ is much less than at $80 \mathrm{ps}$.

\section{Laser launch from Earth to LEO}

Fig. 5 shows our notional flyer design, both for launch to LEO and for interplanetary travel (next section). Diameter is $50 \mathrm{~cm}$. The craft is launched spinning about an axis perpendicular to the beam and very slowly presessing, so that all elements of the surface have equal exposure to the laser beam. A small canister and gas jets produce and maintain these rotations during launch. The mass of the insulation and discardable shell holding the ablator is assumed to be $0.5 \mathrm{~kg}$. For the two cases, the ablator shell will have different $C_{m}$ values and thicknesses. For LEO launch through the atmosphere, as we will see, $\mathrm{C}_{\mathrm{m}}$ will be in the range 110-150 N/MW, while for interplanetary travel $\mathrm{C}_{\mathrm{m}} 1 / 470 \mathrm{~N} / \mathrm{MW}$. As we will show, a craft designed to do both would have two layers: high $\mathrm{C}_{\mathrm{m}}$ to get to LEO and low $\mathrm{C}_{\mathrm{m}}$, for the interplanetary portion of the flight.

In Ref. [2], our method of laser-launching an object to low Earth orbit (LEO) was to separate the problem into two parts. First, we drove vertically through the atmosphere to altitude $h_{o}$, leaving a vertical velocity $\mathrm{v}_{\mathrm{ro}}$. Then, a second laser located at an appropriate distance to satisfy the geometrical constraints applied as much tangential thrust as possible to achieve orbit. This was too complex. Figs. 7 and 8 show the launch geometry for the present work.

\subsection{Equations of motion}

Figs. 6 and 7 show the geometry for launch from Earth to LEO. Here, we include atmospheric drag in the simulations. Referring to Fig. 6 for the symbols, we note that

$\cos ^{1 / 4}\left(\mathrm{r}^{2} p z^{2}-\mathrm{R}^{2}\right) /(2 \mathrm{rz})$

and that the tangential force on the spacecraft from incident laser power $\mathrm{P}$ is

$\mathrm{F}_{\theta} 1 / 4 \mathrm{PC}_{\mathrm{m}} \sin \alpha$, where

$\mathrm{F}^{1 / 4} \mathrm{PC}_{\mathrm{m}^{1 / 4}}(\mathrm{dm} / \mathrm{dt}) \mathrm{v}_{\mathrm{E}}$

is the total force. 


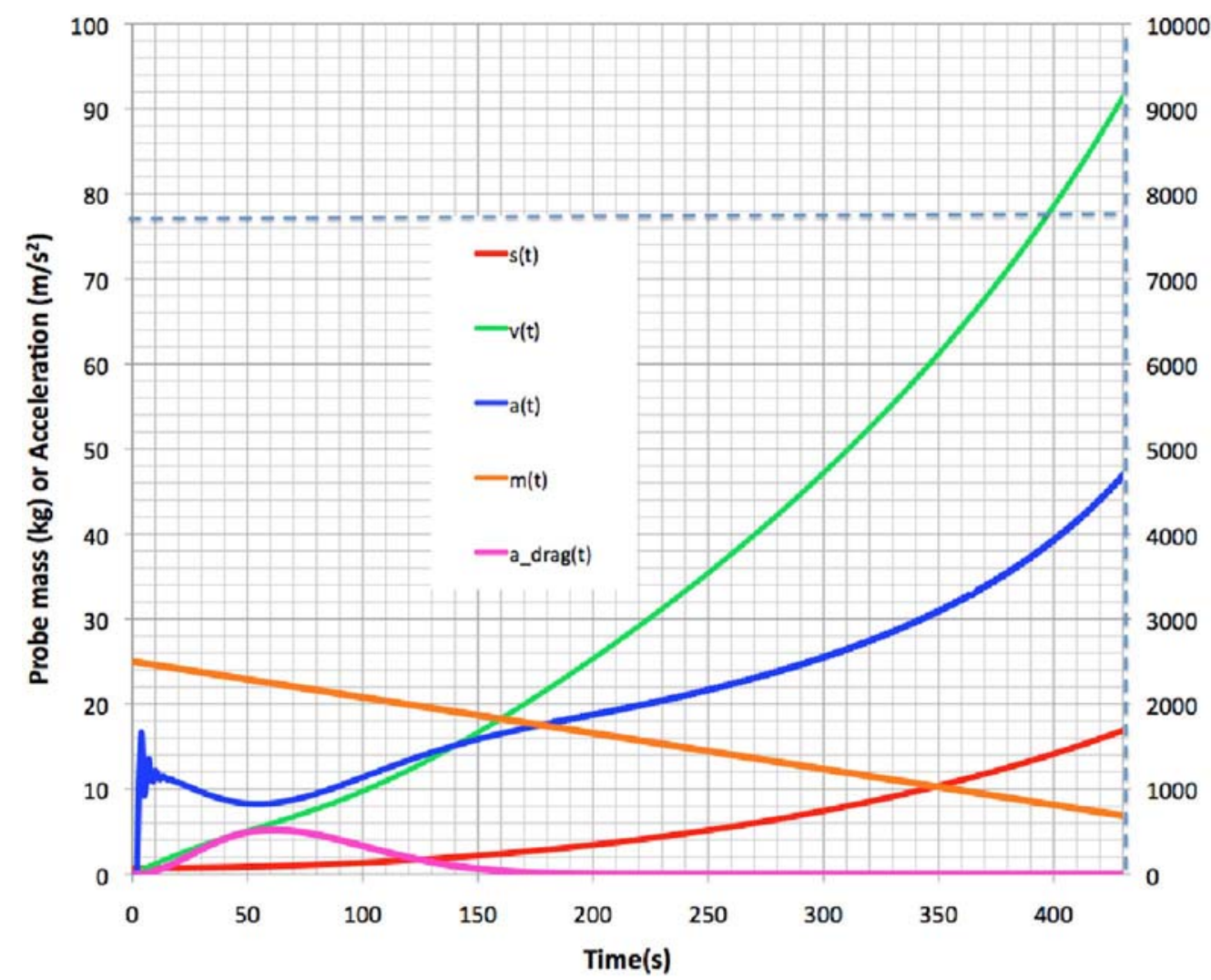

10000

9000

8000

7000

6000

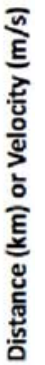

Fig. 9. Case 5. Our only successful single-power laser launch, from $35 \mathrm{~km}$ altitude to $L E O$ with $\mathrm{C}_{\mathrm{m}} 1 / 4130 \mathrm{~N} / \mathrm{MW}$. Flight time $429 \mathrm{~s}$, laser range $\mathrm{s}(\mathrm{t})$. Altitude at insertion is $409 \mathrm{~km}$. Initial zenith angle is $60^{\circ}$ and final zenith angle is $90^{\circ}$. Drag loss is significant, mass ratio delivered to orbit $28 \%$. With final radial velocity $1.47 \mathrm{~km} / \mathrm{s}$ and final velocity $9.09 \mathrm{~km} / \mathrm{s}$, vector velocity slope at insertion is barely acceptable $\left(9.3^{\circ}\right)$ for a successful orbit. Perigee $112 \mathrm{~km}$, apogee $10000 \mathrm{~km}$.

\section{Because}

$d L / d t{ }^{1 / 4} m\left[r\left(d v_{\theta} / d t\right) p(d r / d t) v_{\theta}\right]^{1 / 4} F_{\theta n e t} r^{1 / 4}$ torque,

dividing by $\mathrm{r}$ and including drag,

$\mathrm{F}_{\theta \text { net }} 1 / 4\left(\mathrm{~F}-\mathrm{C}_{\mathrm{d}} A \rho v^{2} / 2\right) \sin \alpha{ }^{1 / 4} \mathrm{~m}\left\{\mathrm{dv}_{\theta} / \mathrm{dtp}[((\mathrm{dr} / \mathrm{dt}) / \mathrm{r})] \mathrm{v}_{\theta}\right\}$,

And $F_{r \text { net }} 1 / 4\left(F-C_{d} A \rho v^{2} / 2\right) \cos \alpha p m\left[v_{\theta}^{2} / r-g \operatorname{gr}_{E}^{2} /(\underset{E}{R} p h)^{2}\right]^{1 / 4} \underset{r d v}{m d t}$

In Eqs. (19) - (24), A 1/4 ( $\pi D p 2 / 4)$ is the exposed cross section area of the spherical flyer, $D p$ is the flyer diameter, $\rho(h)$ is the atmospheric density - an exponential with scale height $7 \mathrm{~km}$ - at altitude $\mathrm{h}$ and $\mathrm{v} 2$ is the sum square of the radial and tangential velocities. In Eqs. (19)-(24), all quantities except the obvious constants are functions of time. $\eta \mathrm{c}$ is a structural efficiency factor to account for the spacial average of the ablation thrust vector, which we take to be 0.8 . Cd is the drag coefficient, vr is vertical velocity, $\mu$ is the target areal mass areal density (to match the dimensions of $\Phi$ ), $\mathrm{P}$ is total laser power on target, and $\mathrm{f}$ is pulse repetition frequency.

\subsection{Initial target altitude and ways to achieve it}

The ways we considered are listed in Table 2. Ultimately, we decided the laser itself is the best method vs. balloons, guns, etc.

\subsection{Launch strategy}

A large number of factors interact to achieve a successful laser launch. Some of these are $\mathrm{Cm}$, flight time, laser range, laser power, delivered mass fraction, final elevation angle, minimum altitude, insertion altitude and laser propagation range. Finding an optimum combination is a matter of art. We found that whatever you do with a laser on the earth's surface, even with the 5-15 MW average power rep-pulse laser which we used here, it is easy to have the target disappear over the horizon before insertion as well as for it to have an undesirable amount of residual radial velocity. Best performance was obtained with $\mathrm{Cm}^{1 / 4} 120-150 \mathrm{~N} / \mathrm{MW}$. Compared to the cases discussed in Ref. [2], this choice increases fuel lifetime [see Eq. (17)].

\subsection{Flights to LEO}

Table 3 and Figs. 8-11 show our results. In our simulations, initial altitudes were chosen as $1,10,15$ and $35 \mathrm{~km}$. Laser beam range was always $<2000 \mathrm{~km}$. The laser station was assumed to be at $3 \mathrm{~km}$ altitude on a mountain so that large zenith angles are more manageable. Acceleration was always modest.

\subsubsection{Single phase flight}

It is difficult to achieve good flight parameters when laser power is applied continuously. Fig. 8 (case 3 in Table 3) shows a bad example, in which launch from $1 \mathrm{~km}$ altitude produces excessive final radial velocity $\mathrm{v}_{\mathrm{rf}}$, and perigee altitude is negative. Fig. 6 makes it clear why this happens. Even if the flight is initially tangent to the Earth's surface, after a long flight, angle $\alpha$ is no longer $\pi / 2$ and an undesirable radial component of thrust exists. A solution is to launch higher.

We were not able to launch from the ground in any single-power flight. In case 3 , beginning at $1 \mathrm{~km}$ altitude also involved significant loss to drag: delivered mass ratio was $23 \%$. In the Fig. 9 flight (Case 5 of Table 3), we launched from $35 \mathrm{~km}$ altitude to minimize energy expended in drag. Even so, only $28 \%$ of the mass survived into LEO despite the $35 \mathrm{~km}$ launch altitude. To avoid excessive $\mathrm{v}_{\mathrm{rf}}$ in a single-power flight, the beam elevation angle must be small, leading to high drag in Case 5, and negative perigee in Case 3. The question of how best to get to $35 \mathrm{~km}$ still remains (Table 2). This was our only successful single-phase flight.

In Table 3, "Chord" is the horizontal distance from the laser station to 


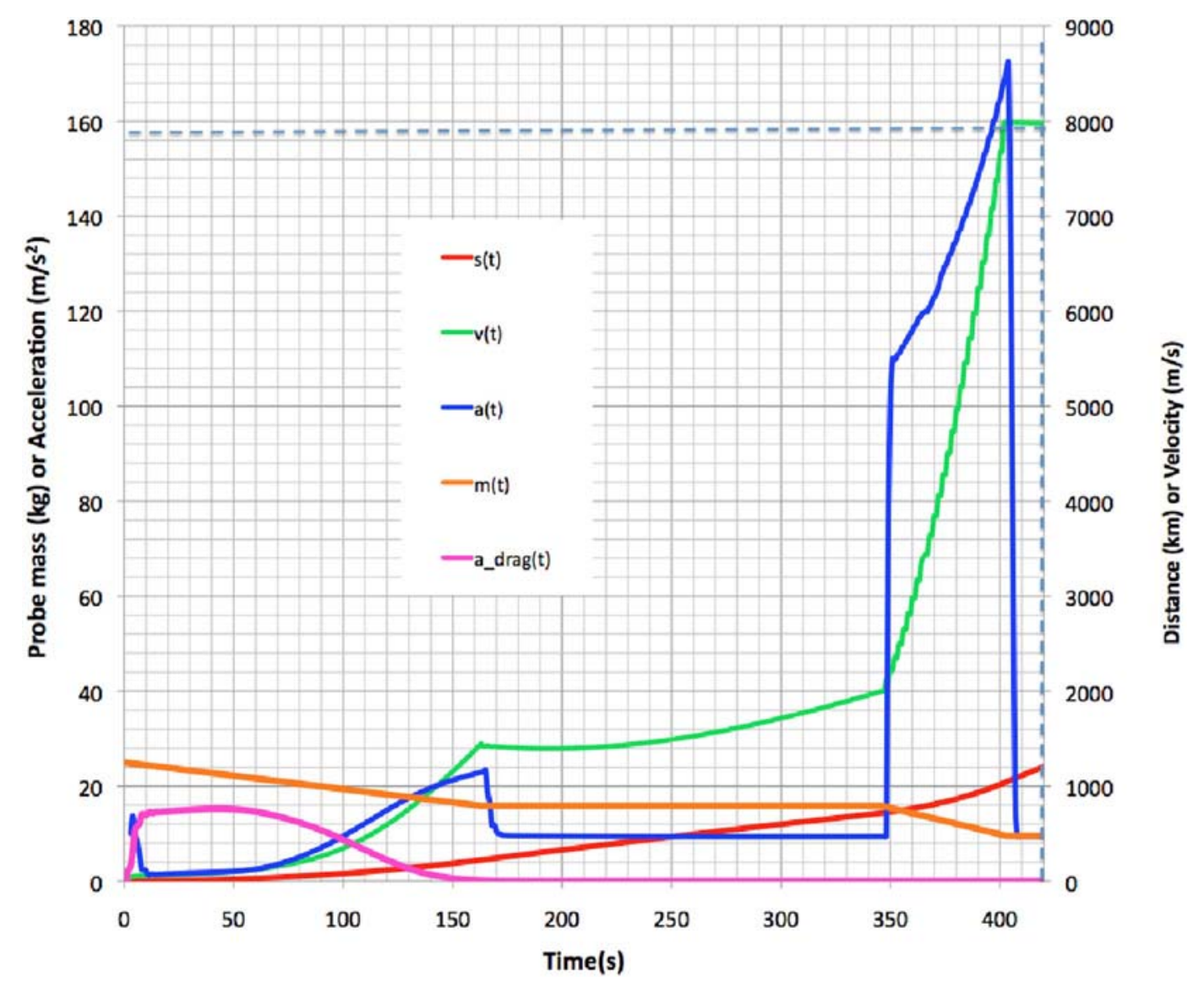

Fig. 10. Case 3A. Laser-launch from $1 \mathrm{~km}$ altitude lasting $160 \mathrm{~s}$ at $5 \mathrm{MW}$ gets us above the atmosphere quickly. Then, a $180 \mathrm{~s}$ coast followed by a $10 \mathrm{MW}$ burst in the last $60 \mathrm{~s}$ gets us into to LEO. $\mathrm{C}_{\mathrm{m}} 1 / 4150 \mathrm{~N} / \mathrm{MW}$. Initial zenith angle is $56^{\circ}$, final zenith angle $90^{\circ}$, mass ratio delivered to orbit $38 \%$. Final radial velocity is $238 \mathrm{~m} / \mathrm{s}$ and final velocity $7.98 \mathrm{~km} / \mathrm{s}$. Perigee is $96 \mathrm{~km}$ and apogee is $842 \mathrm{~km}$.

the point beneath the satellite at launch. $\mathrm{T}$ is flight duration. $\mathrm{T}_{\mathrm{pkdrag}}$ is the time at which drag is maximized. $\phi_{\mathrm{o}}$ and $\phi_{\mathrm{f}}$ are initial and final zenith angles, $h_{o}, h_{p}$ and $h_{a}$ initial, perigee and apogee altitudes, $v_{r f}$ final radial velocity and $\mathrm{s}_{\mathrm{f}}$ final laser range to the spacecraft, $\mathrm{a}_{\max }$ is maximum acceleration, $\mathrm{m}$ is mass delivered to orbit and $\mathrm{M}$ is mass on the ground.

Perigee and apogee altitudes are assessed using Eqs. (25-28). In Eqs. (25)-(26), $\boldsymbol{\mu}$ is the gravitational parameter for Earth (rather than mass areal density), $v_{\mathrm{f}}$ is total velocity, and $\mathrm{v}_{\mathrm{rf}}$ radial velocity at insertion, $\mathrm{g} 1 / 4 \operatorname{asin}\left(\mathrm{v}_{\mathrm{rf}} / \mathrm{v}\right)$, and $\mathrm{C} 1 / 4 \mathrm{r}_{\mathrm{f}} \mathrm{v}_{\mathrm{f}} \cos (\mathrm{g})$, and we have

$$
\text { a } 1 / 4\left(2 / r_{f}-v_{f} / \mu\right)
$$

$\mathrm{e}^{1 / 4}\left[1-C^{2} /(\mu \mathrm{a})\right]^{0.5}$

$r_{a} 1 / 4(1 \mathrm{p} \mathrm{e}) \mathrm{a}$

$r_{p} 1 / 4(1-e) a$

\subsubsection{Three-phase flight}

Now, we use a different technique, in which an initial laser burst gets us above the atmosphere, we coast long enough to develop significant negative radial velocity and then apply a final burst at maximum azimuth angle at 2-3X normal power to achieve orbit with minimum radial velocity. This is called "heat capacity mode operation," in which the laser medium is operated beyond its ability to dissipate heat continuously, for a short time.

Fig. 10 (case 3A) shows results of such a "three-phase flight." Fig. 11 shows that a $45^{\circ}$ initial zenith angle is permitted in a three-phase complex flight profile [Table 3, Case 11B]. For this flight, the $41,700 \mathrm{~km}$ apogee with $54 \%$ of launch mass delivered suggests applications to inspection of GEO satellites.

\subsection{Lasers}

Laser parameters assumed in this work are listed in Table 4. Such high repetition rate, high pulse energy lasers are not yet demonstrated, but are being developed. The state of the art in the lasers we currently need to implement these applications is represented in the HiLASE program [18], ieved $10 \mathrm{~Hz}, 100 \mathrm{~J}$ pulses at 10ns pulse duration. Higher repetition rate in this monolithic laser design and higher capacitycogling are needed. Tens of $\mathrm{kW}$ are available now in $\mathrm{CW}$

priate for laser propulsion. Fiber amplifiers give much better heat dissipation, but $100 \mathrm{k}$ pulsed fibers are necessary to generate $100 \mathrm{~J}$ pulses [15].

We prefer $1057 \mathrm{~nm}$ for the wavelength in atmosphere because absorption is unacceptable at the second and third harmonics, especially at low elevation angles. In space, $355 \mathrm{~nm}$ is ideal. For energy storage, $6 \mathrm{GJ}$, $15 \mathrm{MW}$ super batteries using zinc hybrid cathode technology have now been developed [19]. These batteries can be totally discharged without lifetime penalty. Because $10 \%$ discharge/recharge is the rule for most other battery types to ensure long life, this development increases battery mass efficiency by an order of magnitude.

\subsection{Discussion}

Why are the results here so much better than in Ref. [2]? The main reason is that much larger laser power allows us to oppose gravity with 


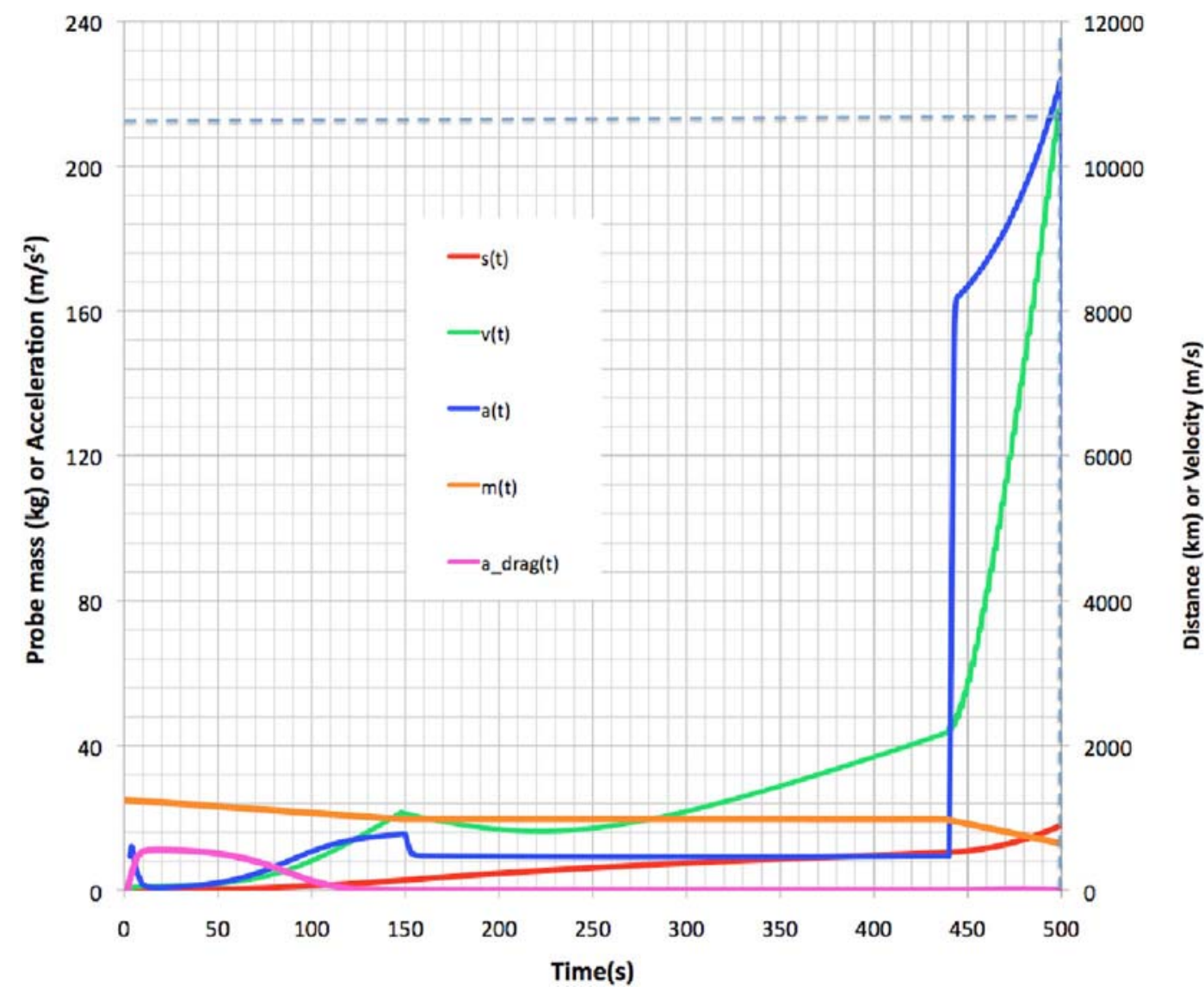

Fig. 11. Case 11B. Fascinating launch from ground ( $1 \mathrm{~km}$ altitude) with $\mathrm{C}_{\mathrm{m}} 1 / 4120 \mathrm{~N} / \mathrm{MW}$. A $300 \mathrm{~s}$ coast followed by a $15 \mathrm{MW}$ burst during $60 \mathrm{~s}$ at the very end gets our craft into orbit. This profile gives $\mathrm{m} / \mathrm{M}$ delivered to orbit of $54 \%(13.5 \mathrm{~kg})$. Initial zenith angle $45.5^{\circ}$, final zenith angle $90^{\circ}$. Final radial velocity is $389 \mathrm{~m} / \mathrm{s}$, final velocity $10.4 \mathrm{~km} / \mathrm{s}$, perigee $104 \mathrm{~km}$, and apogee $41,700 \mathrm{~km}, 117 \%$ of geosynchronous altitude. Insertion slope is $2.12^{\circ}$. Minimal energy is wasted in drag, even though we are starting from the ground.

Table 3

Launch summary. Common parameter: $\mathrm{P} \quad 1 / 4 \quad 5 \mathrm{MW} / \mathrm{n}_{\mathrm{AB}}$. $\mathrm{P}$ doubles or triples at end.

\begin{tabular}{|c|c|c|c|c|c|c|c|c|c|c|c|c|c|}
\hline Case & $\mathrm{C}_{\mathrm{m}} / \mathrm{\eta}_{\mathrm{AB}}(\mathrm{N} / \mathrm{MW})$ & Chord (km) & $\mathrm{T}(\mathrm{s})$ & $\mathrm{T}_{\mathrm{pk} \text { drag }}$ & $\phi_{\mathrm{o}}\left({ }^{\circ}\right)$ & $\phi_{\mathrm{f}}\left({ }^{\circ}\right)$ & $\mathrm{a}_{\max }\left(\mathrm{m} / \mathrm{s}^{2}\right)$ & $\mathrm{v}_{\mathrm{rf}}(\mathrm{km} / \mathrm{s})$ & $\mathrm{m}_{\mathrm{f}} / \mathrm{M}(\%)$ & $\mathrm{h}_{\mathrm{o}}(\mathrm{km})$ & $\mathrm{h}_{\mathrm{p}}(\mathrm{km})$ & $\mathrm{h}_{\mathrm{a}}(\mathrm{km})$ & $\mathrm{s}_{\mathrm{f}}(\mathrm{km})$ \\
\hline 3 & 150 & 1.5 & 344 & 60 & 57 & 84 & 73 & 2.87 & 23 & 1 & -1570 & 4080 & 1270 \\
\hline 5 & 130 & 61 & 429 & 55 & 60 & 90 & 47 & 1.47 & 28 & 35 & 112 & 10,000 & 1680 \\
\hline $3 \mathrm{~A}$ & 150 & 1.5 & 402 & 60 & 56 & 84 & 173 & 0.25 & 38 & 1 & 96 & 842 & 1030 \\
\hline $11 \mathrm{~B}$ & 120 & 1 & 496 & 10 & 45.5 & 90 & 216 & 0.39 & 54 & 1 & 104 & 41,700 & 873 \\
\hline
\end{tabular}

Table 4

Laser and target parameters.

\begin{tabular}{ll}
\hline Type & Diode-pumped Nd \\
\hline Wavelength & $1057 \mathrm{~nm}$ for ground launch, $532 \mathrm{~nm}$ in space \\
Pulse duration & $100 \mathrm{ps}$ \\
Pulse energy & $5 \mathrm{~kJ}$ \\
Pulse repetition rate & $250 \mathrm{~Hz} / 1 \mathrm{kHz} / 2 \mathrm{kHz} / 3 \mathrm{kHz}$ \\
Laser average power $\mathrm{P}_{\mathrm{o}}$ & $1.25-15 \mathrm{MW}$ \\
Target initial mass $\mathrm{m}$ & $25 \mathrm{~kg}$ \\
$\mathrm{C}_{\mathrm{mo}}$ & Various, $70-150 \mathrm{~N} / \mathrm{MW}$ \\
$\mathrm{D}_{\mathrm{b}}$ (Mirror diameter) & $6 \mathrm{~m} / 3 \mathrm{~m}$ \\
\hline
\end{tabular}

smaller $\mathrm{C}_{\mathrm{m}}$, and this leads to better insertion trajectory, higher $\mathrm{I}_{\mathrm{sp}}$ and longer fuel life [Eq. (13)]. This is because higher temperature gives larger mass velocity in the laser-produced jet. Having 300\% of normal power available in a burst at the end of the flight also vastly improves mass delivery, as we show in Table 3. This is our best case for a flight from the ground, with $54 \%$ of mass delivered to LEO (1 km starting altitude). Some calculations showed an $\mathrm{m} / \mathrm{M}$ value of $61 \%$ from a $15 \mathrm{~km}$ starting altitude.

To choose the best flight parameters, there are additional constraints: considering diffraction, scintillation and adaptive optics, maximum permissible range is $2000 \mathrm{~km}$ for $1060 \mathrm{~nm}$ and a 6-m mirror.

This launch technique can easily reach very large apogees. Delivered mass fraction was very impressive. Contrary to our expectations, launching directly through the atmosphere was possible.

\subsection{Energy cost perspective}

For the simulations reported in Fig. 5, the minimum emitted laser beam energy cost per $\mathrm{kg}$ delivered to orbit was $80 \mathrm{MJ} / \mathrm{kg}$. In case $11 \mathrm{~B}$, this cost was $120 \mathrm{MJ} / \mathrm{kg}$. In Ref. [2], we assumed perfect alignment of the beam with the target trajectory, which was supposed to have been achieved with a guidance system and tilting reflectors on the tail of the flyer. In this work, we use a more realistic target that always provides reaction along the beam axis without special mirrors or guidance, but the thrust vector is not perfectly aligned with the path to orbit. This explains the difference in energy cost. The inherent total energy change to create the orbits in Table 3 vary from about $2.4 \mathrm{MJ} / \mathrm{kg}$ to $24 \mathrm{MJ} / \mathrm{kg}$. Riding an 
Fig. 12. A cis-Mars trajectory

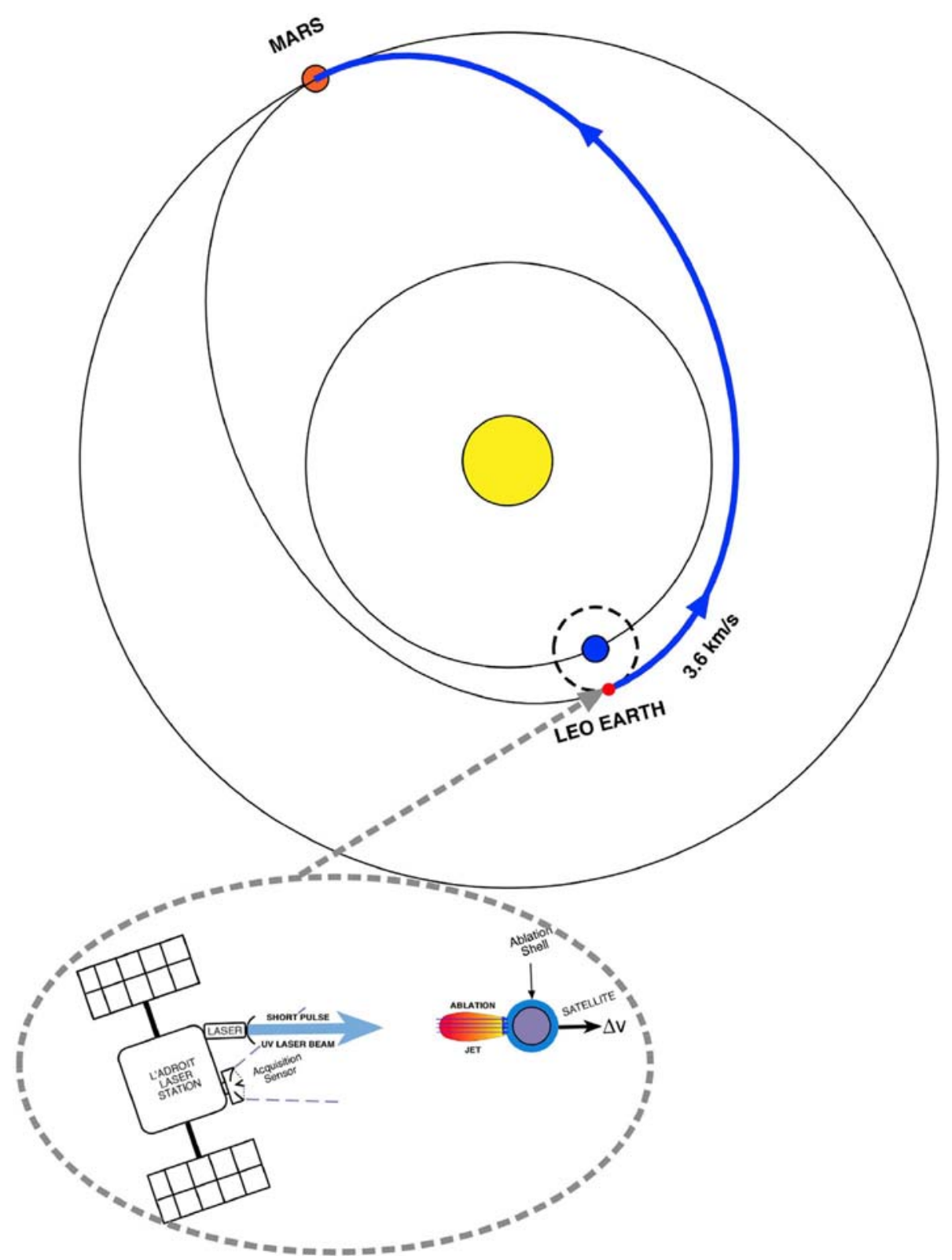

starting from LEO re- quires $\Delta v 1 / 43.6 \mathrm{~km} / \mathrm{s}$.

elevator to $150 \mathrm{~km}$ amounts to $1.5 \mathrm{MJ} / \mathrm{kg}$. A bullet with $7.98 \mathrm{~km} / \mathrm{s}$ velocity contains $32 \mathrm{MJ} / \mathrm{kg}$. The parameter Q in Eq. (8) is related to, but incommensurate with, all these values, because it relates to the mass ablated rather than the mass delivered. Q derived from Eq. (11) for a typical flight at $120 \mathrm{~N} / \mathrm{MW}$ is $140 \mathrm{MJ} / \mathrm{kg}$.

\section{Laser-powered rockets}

In this section, we consider a laser-propelled rocket, consisting of the Fig. 5 flyer. Flight trajectory is shown in Fig. 12. This is an instantaneous launch, from the point of view of the astrodynamics. Here, we don't have to worry about minimum perigee.

\subsection{Equations of motion}

The equation of motion in this case is very simple:

$d^{2} s / d^{2}{ }^{1} / 4 P_{0} C_{m o} \eta_{c} / m$

because there is no drag. The laser and the target are in a micro-G environment in LEO, not on the ground. Because an object launched from LEO as shown in Fig. 13 needs a $\Delta v$ of $3.6 \mathrm{~km} / \mathrm{s}$ to reach its goal, our only problem is to generate this $\Delta v$, rather than worrying about the detailed gravity fields of Earth and the Sun between LEO and Mars. Earth and Sun gravity influence the flight along the way, but all we need to know at the outset is the required $\Delta \mathrm{v}$ and pointing direction, and to deliver it quickly. A flight result is shown in Fig. 13. Mass fraction delivered to Mars is $73 \%$.

\subsection{Discussion}

The laser-powered rocket is an exciting project for future research. This laser is powered from high performance 6 GJ "super-batteries" [19] which are recharged by solar panels in one day at a $70 \mathrm{~kW}$ rate. Laser power is only $1.25 \mathrm{MW}$, not 5 , and can be the third $\mathrm{Nd}$ harmonic $(355 \mathrm{~nm})$ in space. For this reason the mirror can have $3 \mathrm{~m}$ diameter rather than $6 \mathrm{~m}$, as in the LEO launch analysis. Although $\mathrm{C}_{\mathrm{m}}$ and $\mathrm{I}_{\mathrm{sp}}$ have not been measured at $355 \mathrm{~nm}$, theory [ref. (3)] says $C_{m}$ should be better at the shorter wavelength. We remind the reader that the laser power and $\mathrm{C}_{\mathrm{m}}$ values listed in Table 5 should be understood to be adjusted according 


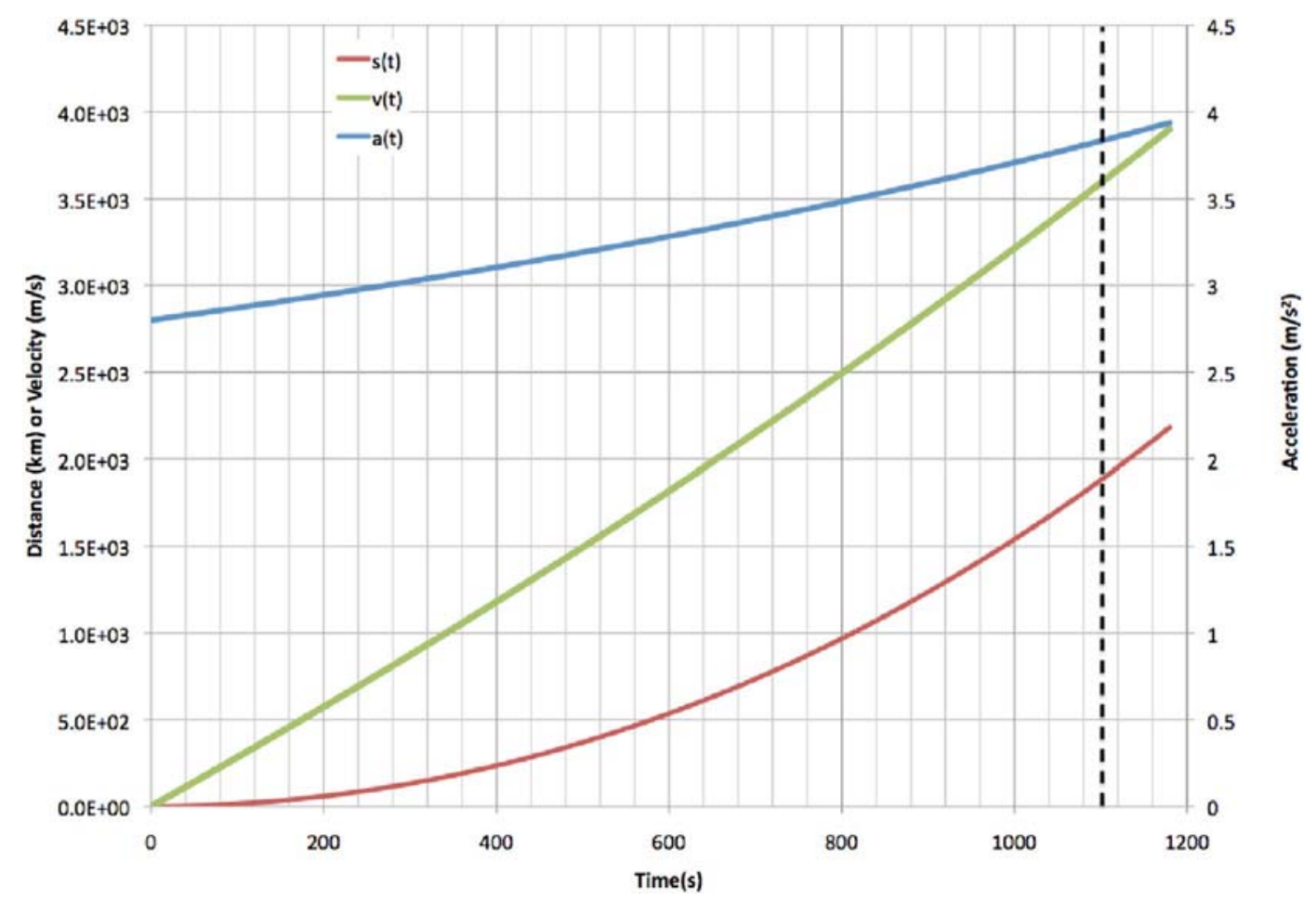

Fig. 13. The necessary velocity of $3.6 \mathrm{~km} / \mathrm{s}$ is obtained after accelerating for $18.5 \mathrm{~min}$, and $18.2 \mathrm{~kg}$ is delivered to the cis-Mars trajectory.

Table 5

Parameters for flight to Mars.

\begin{tabular}{ll}
\hline Wavelength $(\mathrm{nm})$ & 355 \\
\hline Pulse duration $(\mathrm{ps})$ & 100 \\
Pulse energy $(\mathrm{kJ})$ & 5 \\
Repetition rate $(\mathrm{Hz})$ & 250 \\
Average power $(\mathrm{MW})$ & 1.25 \\
$\mathrm{C}_{\mathrm{m}}(\mathrm{N} / \mathrm{MW})$ & 70 \\
Fluence $\Phi\left(\mathrm{kJ} / \mathrm{m}^{2}\right)$ & 35 \\
Target diameter $(\mathrm{cm})$ & 50 \\
Initial mass $(\mathrm{kg})$ & 25 \\
Final mass $(\mathrm{kg})$ & $18.2(73 \%)$ \\
Final velocity $(\mathrm{km} / \mathrm{s})$ & 3.6 \\
Acceleration time $(\mathrm{min})$ & 18.5 \\
Mirror diameter $(\mathrm{m})$ & 3 \\
Maximum range $(\mathrm{km})$ & 1900 \\
Maximum acceleration $\left(\mathrm{m} / \mathrm{s}^{2}\right)$ & 3.84 \\
Ablation efficiency & 1.0 \\
\hline
\end{tabular}

to Eqs. (15)-(16) when ablation efficiencies are known. If such a flight were concatenated with a maximally efficient launch from ground to LEO, total mass fraction would be $39 \%$ from Earth to Mars, using a combination of groundbased and spacebased lasers. But, that's another paper!

\section{Conclusions}

For several years, scientists have been launching thin foils with shortpulse lasers to $8 \mathrm{~km} / \mathrm{s}$ velocities [20]. A way to understand the work reported here is that we launch the equivalent of 400,000 or so thin foils at similar velocities toward the laser beam, one at a time, and the reaction momentum propels a craft in space efficiently.

For the first time, we showed it is possible to laser launch directly from the Earth's surface, and still obtain excellent mass fraction $\mathrm{m} / \mathrm{M}$ greater than $50 \%$ delivered to LEO. This is more than a factor-of- 10 improvement over state of the art $\mathrm{m} / \mathrm{M}$ ratios with chemical rockets. This, an exciting result of this study, can be utilized by assembling larger stations on orbit from pieces, or for launching swarms of micro- or nanosatellites at low cost.

We used a novel design in which a sphere covered with ablation fuel is caused to rotate randomly so that the entire surface is used for fuel, creating a jet which is always directed opposite to the laser beam. Rotation is presumed to be caused by, e.g., gas jets from a small internal canister. The direction of the beam itself governs the direction of the sphere's trajectory.

These are all passive ablation fuels. As we showed in Ref. [11], it is possible to obtain 3-4 times larger $C_{m}$ with energetic materials like glycidyl azide polymer (GAP).

In the absence of accurate data on specific impulse $\mathrm{I}_{\mathrm{sp}}$ for our target materials, we showed that it is still possible to use a scaling with laser power inversely proportional to $\eta_{A B}$ and coupling coefficient $C_{m}$ proportional to $\eta_{\mathrm{AB}}$ to provide constant thrust and fuel lifetime.

Flight times to LEO were $250-540$ s. Initial laser power was $5 \mathrm{MW} / \eta_{\mathrm{AB}}$ and the probe initial mass was $25 \mathrm{~kg}$. In the best cases, a burst of $10-15$ $\mathrm{MW} / \eta_{\mathrm{AB}}$ was applied in the last $80 \mathrm{~s}$, producing a significant increase in $\mathrm{m} / \mathrm{M}$ as well as a better values for final orbit parameters.

If a practical, low-cost way (balloon, gun, tall tower) is developed to lift the flyers to $15 \mathrm{~km}$ before laser acceleration, we showed even better $\mathrm{m} / \mathrm{M}$ values for the overall flight. The cost of doing this may not be worthwhile. The gains for initiating the flight at $35 \mathrm{~km}$ rather than $15 \mathrm{~km}$ are probably not worth the additional effort.

Our calculations show that this technology, combined with a 1B\$ groundbased laser station capable of 30 launches/day, can reduce launch costs to LEO to about $\$ 300 / \mathrm{kg}$, a factor of 30 below present experience, because station cost is dominant at high launch rate.

An important application of this work is to launching constellations of Earth-observing microsatellites, to more carefully monitor global climate change and its consequences, in order to spot trends at the earliest possible time and to develop very highly detailed global models. Another application is to sending inspection craft to geosynchronous (GEO) orbit.

The second important result of this work is that it is not difficult to send a probe to Mars in a year or so, with $73 \%$ of the mass surviving. Laser wavelength should be the $\mathrm{Nd} 3 \mathrm{rd}$ harmonic in this case $(355 \mathrm{~nm})$ because of its better $\mathrm{C}_{\mathrm{m}}$ and lower divergence, making possible smaller 
mirrors than for the LEO launch case. Maximum laser range was $2000 \mathrm{~km}$.

Further applications of this work are to longer flights within the solar system on one extreme of difficulty, and to placing satellites in LEO or GEO orbits on the other. As higher power lasers are developed, larger masses than $25 \mathrm{~kg}$ can also be laser-launched.

Because of Eq. (18), almost any goal can be reached starting from LEO with a sufficiently small $\mathrm{C}_{\mathrm{mo}}$, and sufficient laser power.

\section{Acknowledgments}

This paper is the written version of Paper no. 679, presented at the 7th European Conference for Astronautics and Space Sciences (EUCASS), Politecnico di Milano, 3-6 July 2017.

The research of my coauthors developing the Table 1 data and exploring a new area in Space Science was partly funded by the CNES through grant AVP-CT-0-1603. The authors thank the LULI Program Committee for having allocated pluriannual beamtime for us to use the ELFIE facility 16TW-F6.

C. R. Phipps benefited immensely from discussions with coauthors, especially Messrs. Bonnal and Masson during development of this topic. C. R. Phipps' work did not receive any specific grant from funding agencies in the public, commercial, or not-for-profit sectors.

\section{Appendix A. Supplementary data}

Supplementary data related to this article can be found at https://doi.org/10.1016/j.actaastro.2018.02.018.

\section{Acronyms and abbreviations}

Table 6: Acronyms and abbreviations used in this work.

\begin{tabular}{|c|c|}
\hline CEA & Commissariat à l'hiergie Atomique et aux '́nergies Alternatives \\
\hline CEMEF & Centre de Mise en Forme des Materiaux \\
\hline CESTA & Centre d'itudes Scientifiques et Techniques d'Aquitaine \\
\hline CNES & Centre National d'tiudes Spatiales \\
\hline CNRS & Centre National de la Recherche Scientifique \\
\hline DAM & Direction des Applications Militaires \\
\hline DIF & DAM Île-de-France \\
\hline DiPOLE & High repetition rate laser developed by the Rutherford Appleton Laboratory \\
\hline DIY & Do-it-yourself \\
\hline GAP & Glycidyl azide polymer \\
\hline GEO & Geosynchronous orbit \\
\hline HiLASE & High repetition rate European Union laser project in the Czech Republic \\
\hline IKAROS & Interplanetary Kite-craft Accelerated by Radiation of the Sun \\
\hline JAXA & Japan Aerospace Exploration Agency \\
\hline LEO & Low Earth Orbit \\
\hline LLC & Limited Liability Corporation \\
\hline LULI & Laboratoire pour l'Utilisation des Lasers Intenses ('Eole Polytechnique) \\
\hline $\mathrm{Nd}$ & Neodymium lasing medium in glass or other host \\
\hline POM & Polyoxymethylene, trade name Delrin ${ }^{\circledR}$ \\
\hline
\end{tabular}

\section{References}

[1] C.R. Phipps, M. Michaelis, LISP, J. Laser Part. Beams 12 (1) (1994) 23-54.

[2] C.R. Phipps, J. Reilly, J. Campbell, Optimum parameters for laser-launching objects into low earth orbit, J. Laser Part. Beams 18 (4) (2000) 661-695.

[3] C.R. Phipps, C. Bonnal, A spaceborne, pulsed UV laser system for re-entering or nudging LEO debris, and re-orbiting GEO debris, Acta Astronaut. 118 (2016) 224236.

[4] F. Tsander, Flight to other planets, in: Ye Moshkin (Ed.), Development of Russian Rocket Technology, Mashinostroyeniye Press, Moscow, 1924 (1973) (in Russian).

[5] K. Tsiolkovsky, Plan of Space Exploration, 1926 (in Russian), available in English in "Exploration of the Universe with Reaction Machines: Exploring the Unknown," NASA History Series. NASA SP 4407, Washington, D.C. (1995).

[6] H. Oberth, Die Rakete zu den Planetenræumen (The Rocket to the Planet Spaces), Oldenbourg Verlag, München, 1923.

[7] E. S@inger, Zur Theorie der Photonenraketen, Probleme der Weltraumforschung (IV), in: Internationaler Astronautischer Kongress, Zürich 1953; S. 32, Laubscher, Biel-Bienne, 1955.

[8] C.R. Phipps, Pulsed lasers for clearing debris in LEO and GEO, paper LSSE1-1, in: Optics and Photonics International Conference, Yokohama, 17-20 May 2016, 2016.

[9] C.R. Phipps, M. Birkan, W. Bohn, H.-A. Eckel, H. Horisawa, T. Lippert, M. Michaelis, Y. Rezunkov, A. Sasoh, W. Schall, S. Scharring, J. Sinko, Review: laser ablation propulsion, J. Propul. Power 26 (4) (2010) 609-637.

[10] H. Yano, Cosmic dust detection by the IKAROS large area dust detectors ion interplanetary space from the Earth to Venus, in: 42nd Lunar and Planetary Science Conference, 2011 [in Japanese].

[11] C.R. Phipps, J. R.Luke, W. Helgeson, Laser-powered, multi-Newton thrust space engine with variable specific impulse, in: High-Power Laser Ablation VII, Proceedings of SPIE 7005, 1X1-1X-8, 2008.
[12] C.R. Phipps, J.R. Luke, Laser space propulsion, in: Laser Ablation and its Applications, Chap.16, Springer, 2007, pp. 407-434.

[13] C.R. Phipps, J.R. Luke, D. Funk, D. Moore, J. Glownia, T. Lippert, Laser impulse coupling at 130fs, Appl. Surf. Sci. 252 (2006) 4838-4844.

[14] Courtesy of H.-A. Eckel, DLR Stuttgart, 2016.

[15] C.R. Phipps, M. Boustie, J.-M. Chevalier, S. Baton, E. Bambrink, L. Berthe, M. Schneider, L. Videau, S.A.E. Boyer, S. Scharring, Laser impulse coupling and ablated mass measurements at $400 \mathrm{fs}$ and $80 \mathrm{ps}$ using the LULI facility at $1057 \mathrm{~nm}$ wavelength, J. Appl. Phys. 122 (2017) 193103, https://doi.org/10.1063/ 1.4997196 .

[16] L.N. Myrabo, D.G. Messitt, F.B. Mead Jr., Ground and flight tests of a laser propelled vehicle, paper AIAA 98-1001, in: 36th AIAA Aerospace Science Meeting \& Exhibit, 1998, 12-15 January 1998, Reno, NV.

[17] L.N. Myrabo, World record flights of beam-riding rocket lightcraft: demonstration of 'disruptive' propulsion technology, paper AIAA 2001-3798, in: 37th AIAA/ ASME/SAE/ASEE Joint Propulsion Conference, 2001, 8-11 July 2001, Salt Lake City, UT.

[18] HiLASE Project, Czechia, Advanced DPSSL Laser, DiPOLE 100, Delivers 1kW Performance, 2016. http://www.hilase.cz/en/advanced-dpssl-laser-dipole-100delivers-1 kw-performance/.

[19] See https://eosenergystorage.com/products-technology/ for high energy density ZNYTH Zinc Hybrid Cathode Technology.

[20] Z. Gong, et al., Experimental Study for Laser-driven Flyer Plates up to $8 \mathrm{~km} / \mathrm{s}$, International Astronautical Federation, 2015 paper IAC-15, A6,3,8,x29049.

C. R. Phipps earned a Ph.D. from Stanford University in 1972 and B.S. and M.S. degrees from the Massachusetts Institute of Technology. He worked at Lawrence Livermore Laboratory and Los Alamos National Laboratory before forming Photonic Associates, LLC in 1995. His interest in laser propulsion goes back to that year. 